\title{
TRATAMENTO CIRÚRGICO MULTIDISCIPLINAR EM PACIENTE POLITRAUMATIZADO DE FACE: RELATO DE CASO
}

José Domingos FRAIZ; Ingrid Araújo de OLIVEIRA; Nelson Luis Barbosa REBELLATO; Delson João da COSTA; Paulo Roberto MÜLLER

O conceito atual de atendimento hospitalar e de emergência ao paciente politraumatizado de face exige conhecimento avançado de procedimentos salvadores por todos da equipe em uma unidade de urgência e emergência. No atendimento ao traumatizado é importante compreender detalhadamente os princípios de avaliação e do tratamento das injúrias faciais. Nesse trabalho será apresentado o protocolo de atendimento ao paciente politraumatizado de face adotado no serviço de cirurgia e traumatologia buco-maxilo-facias do Hospital XV. Segundo Sicher e Tandler 1928 as chaves para o sucesso do tratamento do trauma panfacial, consiste em uma boa exposição do campo operatório e cuidadosa redução e fixação das fraturas faciais, que pode ser feito com a utilização de placas e parafusos de titânio. De acordo com Champy et al 1999 devido ao grande número de protocolos utilizados mundialmente; o fator claro na linha de pensamento de todos os cirurgiões, é a de que a seqüência deve ser baseada em um cuidadoso diagnóstico. No presente caso paciente do sexo masculino, leucoderma, 46 anos, foi atendido pelo serviço de cirurgia e traumatologia bucomaxilo-faciais do hospital XV, apresentando fraturas múltiplas de crânio e face, tendo como etiologia a explosão de um pneu de caminhão cujo aro interno da roda foi projetado contra a cabeça do paciente. 